\title{
The Development of Integration Network Structures in the Regional Industry
}

\author{
Andrey Plakhin ${ }^{2, *}$, Maria Selezneva ${ }^{2}$, Yashar Salamzadeh $^{1}$, Tatiana Guseva ${ }^{2}$, \\ Alexander Kudryavtsev ${ }^{2}$ \\ ${ }^{1}$ Graduate school of business, Universiti Sains Malaysia, Malaysia \\ ${ }^{2}$ Ural State University of Economics, Ekaterinburg, Russia \\ *Corresponding author. Email: apla@usue.ru.
}

\begin{abstract}
The relevance of the study is due to the need to solve the problem of identifying participants in network relationships for the purpose of subsequent research. This study was carried out within the framework of a network methodology, the development of the provisions of which is carried out on the basis of stakeholder and institutional approaches, which, by studying various collective forms of influence, form management tools for organizing networks in the economy, as well as innovation systems, industries and business clusters. In the course of approbation of the methodology for identifying subjects of network interaction in the industry of the region on the territory of the Sverdlovsk region, a network integrative structure was revealed in the industry "Production of drugs and materials used for medical purposes" uniting twelve economic entities that are legally independent from each other and have long-term contractual relationships, within the framework of which supplies of resources are made and eight economic entities that are intermediate consumers of products.
\end{abstract}

Keywords: теория strategic, network subject, contractual relationship, network configuration, network theory.

\section{INTRODUCTION}

The development of contractual relations has led to the formation of stable network structures that have replaced the traditional unitary forms of integration, which imply the combination of assets and production systems within a single economic complex. In Russia, such an organizational form of activity is observed when creating a common infrastructure base, designed for special economic zones, industrial parks, business incubators, technology platforms, ecosystems. The application of the network methodology in the management of the activities of economic entities is based on the identification and targeted distribution of internal and external additional effects formed in the process of interaction between network participants.

The network form of business integration is actively developing on the basis of an evolutionary transition to digital technologies, which makes it possible to quickly assess the advantages of a particular counterparty and the corresponding benefits from entering the network structure [1]. The network methodology has become widespread in the information and digital platform-based service industries. At the same time, the network form of business integration is also used in industry, however, the study of this issue occurs mainly in the context of violations of competitive relations by network entities, rather than studying the positive effects of this form of interaction [2]. Thus, research is needed to determine the coordinating role of the network interaction of industrial enterprises, allowing us to consider this form of integration fromation from the standpoint of the generated benefits.

The purpose of the article is to test the methodology for identifying subjects of network interaction in the industry of the Sverdlovsk region.

The methodology of network theory, the main provisions of which are presented in [3], makes it possible to study the complexes of interconnected industrial enterprises as an integration object that has a common resource base and a common economic result. As noted in the works [8,9], numerous interpretations of the concept of a "network of business entities" highlight two main features of this object, these are the presence of stable partnerships and the legal independence of the entities included in the network. 
As noted in works $[4,5,6]$, an important feature of network interaction from other forms of economic integration is the coordination of the activities of the subjects through the mutual adaptation of the interests of the network participants instead of the tools of hierarchical influence.

In work [7], "a theoretical structure describing integration relationships as a strategic network provides additional opportunities for improving the methodology for managing joint activities of business entities, while providing for both the need to maintain a balance of interests in common goals to ensure the sustainable functioning of the entire network, and opportunities for mutual influence and the corresponding influence of some subjects on others for individual purposes ". Also important is the methodological toolkit that allows to use network effects as a tool to influence network participants [8].

In the work of Ritter T., Wilkinson I. F., Johnston W. J. [9] approaches to the identification of subjects of network interaction, depending on the characteristics of connections between the subjects, are determined. The first form examines a separate subject of the network and its connections with other firms and organizations that require coordination. In addition, within each subject of interaction, the networks of relationships between people and business units are considered, which determine the possibility of choosing a strategy.

In the second form of network interaction, the object is an individual pair of independent subjects.

The third form of networking involves a level of interrelated relationships in which the entity is not directly involved, such as indirect relationships between a firm and its client's customers or a supplier's suppliers. The problem of management here includes consideration of the indirect effects of managerial actions in one relationship on other relationships in the network, including responding to opportunities and problems arising from actions taking place in related relationships. The role of relationships as bridges or conductors to other relationships becomes important, giving rise to various types of indirect network functions of relationships.

The fourth form of network interaction considers a network that has its own identity, formed by certain institutional frameworks, for example, a system of contracts. This form is created as a result of interactions between network participants and their strategies, including interactions between firms and within companies and other types of organizations (government entities), as well as business and non-profit interactions.

From the given conceptualization of the network relationships forms, we can conclude about a certain hierarchy of network objects management:

- $\quad$ at the level of an individual,
- $\quad$ at the business unit level,

- $\quad$ at the company level,

- $\quad$ at the level of the institutional regulator.

The development of the methodology for researching networks of industrial enterprises is aimed at identifying competitive and cooperative forms of interaction between business entities and the formation of effective strategies for network interaction. Solving the problem of identifying stable links will allow to isolate the objects included in the strategic network and create an information base for further research.

\section{METHODS}

Based on the theoretical provisions on the understanding of the strategic network as a complex of interconnected entities that have partnerships while maintaining the independence of activities and the main incentive of these entities to create a network integration formation - the possibility of obtaining internal and external additional effects, we will proceed to the formation of methodological support for the definition and analysis of the network business-integration objects. Figure 1 shows the algorithm of the developed technique.

Let's consider the stages of the technique. At the first stage, it is necessary to identify the subjects of the strategic network, which, in accordance with the provisions of the network theory, took advantage of the presence of positive network effects, were able to exceed the industry average values in revenue, investment and capital growth. This approach makes it possible to determine the subjects at different stages of the life cycle, so the indicator of the growth of assets above the industry average value will allow identifying the subjects of network integration formation at the stage of the beginning of activity, the excess of the industry average value of the indicators of profitability of sales and costs makes it possible to identify the subjects of network integration formation at the growth stage, and the value of the ratio of gross profit to assets of the company at the stage of maturity and recession. Also, the use of these indicators will make it possible to link the identified subjects with the parameters of institutional incentives. 


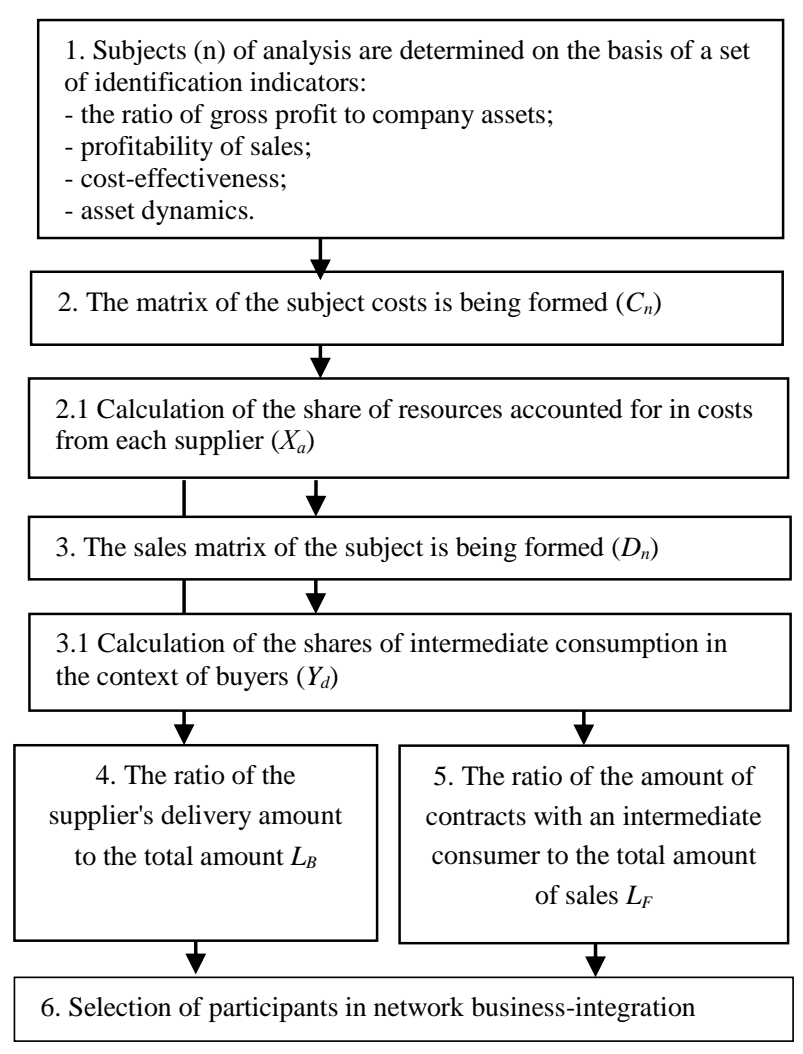

Figure 1 Algorithm of the methodology for identifying subjects of network interaction in the regional industry

At the second stage of the methodology, a matrix of costs of the identified subjects is compiled in order to determine the connections of the previous stages of the network integrative structure. The matrices are analyzed by determining the proportion of resources attracted from each supplier (formula 1), which is the basis for determining the significance of the network connection with the supplying entities.

$$
X_{a}=C_{n} /\left(\sum C_{n}\right)
$$

$X_{a}$ - share of resources accounted for in costs from each supplier

$C_{n}$ - costs of the subject of the network integrative structure

At the third stage of the methodology, a sales matrix of the identified subjects is drawn up in order to determine the connections of the subsequent stages of the network integrative structure. The matrices are analyzed by determining the proportion of sales to each intermediate consumer, that is, an independent participant in the strategic integrative structure (formula 2), which is the basis for determining the significance of the network connection with the supplying entities.

$$
Y_{d}=D_{n} /\left(\sum D_{n}\right)
$$

$Y_{d}-$ share of intermediate consumption by buyers

$D_{n}$ - sales of the subject of a network integrative structure

At the fourth stage, an analysis takes place to measure the degree of interconnectedness of participants in a network integration structure, for this, the $L_{B}$ coefficient is used - the ratio of the supplier's supply amount to the total amount by type of activity (formula 3):

$$
L_{B}=\left(\sum(j=c)^{\wedge}(j=h) x_{-} i j+\ldots+\sum(j=h)^{\wedge}(j=c) x_{i j}\right) /\left(C_{c}+\ldots+C_{h}\right)
$$

$c \ldots h$-grouped suppliers.

At the fifth stage of the methodology, the measurement of the degree of interconnectedness of the network integration structure is analyzed; for this, the $L_{F}$ coefficient is used - the ratio of the amount of contracts with an intermediate consumer to the total amount of sales by type of activity (formula 4):

$$
\begin{gathered}
L_{F}=\left(\sum(j=p)^{\wedge}(j=q) y_{i j}+\ldots+\sum(j=q)^{\wedge}(j=p) y_{-} i j\right. \\
) /\left(D_{p}+\ldots+D_{q}\right)
\end{gathered}
$$

$p \ldots q$-grouped intermediate consumers.

At the sixth stage of the methodology, the subjects of the strategic network are selected based on the relative strength of the connection of each subject with the identified subject of the network integrative structure with manifested network effects. Despite the fact that in factor analysis only relationships with an absolute value of more than 0.50 are considered, in order to identify and interpret the strength of industry ties, relationships with an absolute value of more than 0.35 were considered. Values ranging from 0.35 characterized the most strongly connected participants; from 0.15 to 0.35 - moderately related; less than 0.15 not included in the network integrative structure.

\section{RESULTS}

As a result of the implementation of the first stage of the methodology, data were obtained on possible participants in network business integration on the territory of the Sverdlovsk region. The analysis made it possible to identify four subjects that, even in crisis conditions, showed an increase in indicators operating in the following industries:

- $\quad$ production of ready-made feeds for animals kept on farms;

- $\quad$ production of drugs and materials used for medical purposes; 
- manufacture of plastic products for packaging goods;

- manufacture of other outerwear.

The presented data indicate that the identified subjects over the past three years demonstrate the values of identification indicators above the industry average values, therefore, it can be concluded that there are factors that allow the formation of additional value.

Assessing the constancy of the company's ties, it is necessary to note the presence of constant supplies from enterprises related to the following activities:

- activities of agents in the wholesale trade of industrial and technical chemicals;

- production of medicinal products;

- production of pharmaceutical substances;

- wholesale trade in pharmaceutical products.

Further, in accordance with the fourth stage of the methodology, we will determine the significance of the links, table 1 .
Table 1. Determination of the relevance of feedbacks of an integrative network structure.

\begin{tabular}{|c|c|}
\hline Activity / Supplier & $\mathrm{L}_{\mathrm{B}}$ Ratio \\
\hline \multicolumn{2}{|c|}{$\begin{array}{l}\text { Activities of agents in the wholesale trade of industrial and } \\
\text { technical chemicals }\end{array}$} \\
\hline $\mathrm{X} 11$ & 0,2 \\
\hline $\mathrm{X} 12$ & 0,32 \\
\hline $\mathrm{X} 13$ & 0,06 \\
\hline $\mathrm{X} 14$ & 0,03 \\
\hline X15 & 0,08 \\
\hline $\mathrm{X} 16$ & 0,07 \\
\hline $\mathrm{X} 17$ & 0,03 \\
\hline $\mathrm{X} 18$ & 0,2 \\
\hline \multicolumn{2}{|c|}{ Production of medicinal products } \\
\hline $\mathrm{X} 21$ & 0,02 \\
\hline $\mathrm{X} 22$ & 0,25 \\
\hline $\mathrm{X} 23$ & 0,01 \\
\hline $\mathrm{X} 24$ & 0,01 \\
\hline $\mathrm{X} 25$ & 0,01 \\
\hline $\mathrm{X} 26$ & 0,01 \\
\hline $\mathrm{X} 27$ & 0,01 \\
\hline $\mathrm{X} 28$ & 0,05 \\
\hline $\mathrm{X} 29$ & 0,09 \\
\hline $\mathrm{X} 30$ & 0,07 \\
\hline $\mathrm{X} 31$ & 0,01 \\
\hline $\mathrm{X} 32$ & 0,01 \\
\hline $\mathrm{X} 33$ & 0,01 \\
\hline $\mathrm{X} 34$ & 0,15 \\
\hline $\mathrm{X} 35$ & 0,06 \\
\hline $\mathrm{X} 36$ & 0,15 \\
\hline $\mathrm{X} 37$ & 0,08 \\
\hline \multicolumn{2}{|c|}{ Production of pharmaceutical substances } \\
\hline $\mathrm{X} 31$ & 0,35 \\
\hline $\mathrm{X} 32$ & 0,03 \\
\hline $\mathrm{X} 33$ & 0,12 \\
\hline $\mathrm{X} 34$ & 0,06 \\
\hline $\mathrm{X} 35$ & 0,06 \\
\hline $\mathrm{X} 36$ & 0,01 \\
\hline $\mathrm{X} 37$ & 0,01 \\
\hline $\mathrm{X} 38$ & 0,01 \\
\hline $\mathrm{X} 39$ & 0,15 \\
\hline $\mathrm{X} 40$ & 0,15 \\
\hline $\mathrm{X} 41$ & 0,01 \\
\hline $\mathrm{X} 42$ & 0,01 \\
\hline $\mathrm{X} 43$ & 0,01 \\
\hline $\mathrm{X} 44$ & 0,01 \\
\hline $\mathrm{X} 45$ & 0,01 \\
\hline \multicolumn{2}{|c|}{ Wholesale trade in pharmaceutical products } \\
\hline $\mathrm{X} 41$ & 0,01 \\
\hline $\mathrm{X} 42$ & 0,01 \\
\hline $\mathrm{X} 43$ & 0,25 \\
\hline $\mathrm{X} 44$ & 0,24 \\
\hline $\mathrm{X} 45$ & 0,25 \\
\hline $\mathrm{X} 46$ & 0,02 \\
\hline $\mathrm{X} 47$ & 0,22 \\
\hline
\end{tabular}


As can be seen from the table, 13 suppliers have features of a stable connection. The results obtained allow to conclude that there are stable links and the possibility of analyzing the impact of institutional incentives on the formation of the investigated integrative network structure.

Next, we present data for analyzing the stability of relations with intermediate consumers, table 2.

Table 2. Determination of the relevance of direct links of an integrative network structure

\begin{tabular}{|c|c|}
\hline Activity / Intermediate Buyer & $\mathrm{L}_{\mathrm{F}}$ Ratio \\
\hline \multicolumn{2}{|c|}{ Wholesale trade in perfumery and cosmetic products } \\
\hline Y11 & 0,09 \\
\hline $\mathrm{Y} 12$ & 0,21 \\
\hline $\mathrm{Y} 13$ & 0,17 \\
\hline $\mathrm{Y} 14$ & 0,35 \\
\hline $\mathrm{Y} 15$ & 0,09 \\
\hline Y16 & 0,01 \\
\hline Y17 & 0,01 \\
\hline $\mathrm{Y} 18$ & 0,01 \\
\hline Y19 & 0,06 \\
\hline \multicolumn{2}{|c|}{ Retail sale of medicines in specialized stores (pharmacies) } \\
\hline $\mathrm{Y} 21$ & 0,2 \\
\hline $\mathrm{Y} 22$ & 0,35 \\
\hline $\mathrm{Y} 23$ & 0,23 \\
\hline $\mathrm{Y} 24$ & 0,1 \\
\hline $\mathrm{Y} 25$ & 0,06 \\
\hline $\mathrm{Y} 26$ & 0,06 \\
\hline \multicolumn{2}{|c|}{ Wholesale trade of pharmaceutical products } \\
\hline Y31 & 0,01 \\
\hline $\mathrm{Y} 32$ & 0,01 \\
\hline $\mathrm{Y} 33$ & 0,01 \\
\hline $\mathrm{Y} 34$ & 0,01 \\
\hline Y35 & 0,22 \\
\hline Y36 & 0,15 \\
\hline Y37 & 0,08 \\
\hline $\mathrm{Y} 38$ & 0,01 \\
\hline Y39 & 0,01 \\
\hline $\mathrm{Y} 40$ & 0,11 \\
\hline $\mathrm{Y} 41$ & 0,07 \\
\hline $\mathrm{Y} 42$ & 0,09 \\
\hline $\mathrm{Y} 43$ & 0,06 \\
\hline Y44 & 0,08 \\
\hline $\mathrm{Y} 45$ & 0,09 \\
\hline
\end{tabular}

As can be seen from the table, 8 intermediate buyers have features of a stable connection. Next, we present a general diagram of connections of an integrative network structure, Figure 2.

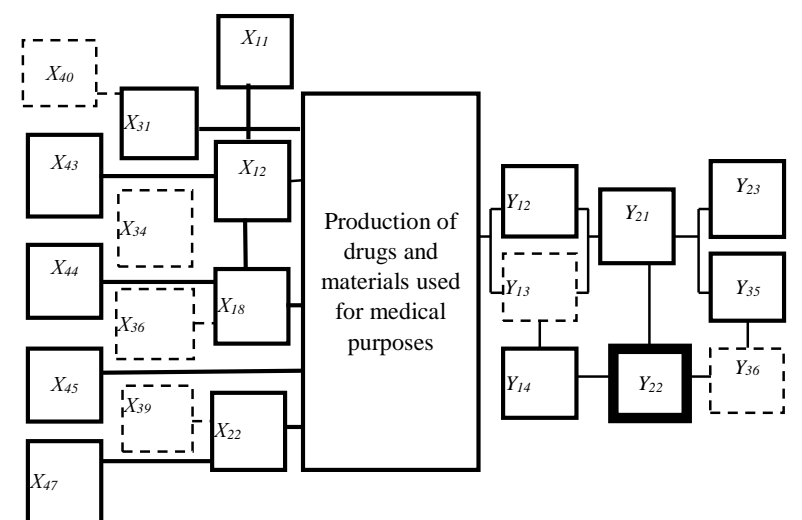

Figure 2 General diagram of the configuration of an integrative network structure.

As can be seen in Figure 2, the integrative structure has a concentrated form, with feedbacks being more differentiated than those with sales organizations.

\section{CONCLUSIONS}

Thus, in the course of approbation of the methodology for identifying subjects of network interaction in the regional industry on the territory of the Sverdlovsk region, a network integrative structure was revealed in the industry of "Production of drugs and materials used for medical purposes" uniting thirteen economic entities that are legally independent from each other and have long-term contractual relationship, within the framework of which the supply of resources and eight economic entities, which are intermediate consumers of products, are made.

\section{ACKNOWLEDGMENTS}

The publication was prepared with the financial support of a research grant from the Russian Foundation for Basic Research and the Sverdlovsk Region No. 20410-660032 r_a

\section{REFERENCES}

[1] M. Kompaniets, A. Plakhin, M. Selezneva, T. Kochergina, M. Khokholush, Analysis of the scientific and technical level of production and the introduction of innovation technologies in the oredressing plant. In: E3S Web of Conferences, 2020, p. 208.

[2] R. Gulati, N. Nohria, A. Zaheer Strategic networks Springer, 2006.

[3] J. Planko, J. Cramer, M. P. Hekkert, M. M. Chappin Combining the technological innovation systems framework with the entrepreneurs' perspective on innovation. In: Technology Analysis \& Strategic Management, 6 (2017)

[4] A. I. Afonichkin, E. A. Afonichkina, A. M. Toporkov Modeling of cluster economic systems in 
the form of a network structure (business-network) . In: Bulletin of the Volga University named after V.N. Tatishchev, 1 (2016).

[5] S. Laari-Salmela, T. Mainela, V. Puhakka Beyond network pictures: Situational strategizing in network context. In: Industrial Marketing Management, 45 (2015).

[6] K. Möller, S. Svahn How to influence the birth of new business fields-Network perspective. In: Industrial Marketing Management, 4 (2004).

[7] E. V. Popov, K. A. Semyachkov, V. L. Simonova Modeling of conditions for the development of network structures. In: UrFU Bulletin. Series: Economics and Management, 3 (2016).

[8] R.E. Kranton, D.F. Minehart Networks versus vertical integration. In: The RAND Journal of Economics, 3 (2000).

[9] T. Ritter, I. F. Wilkinson, W. J. Johnston Managing in complex business networks. In: Industrial marketing management, 3 (2004). 